\title{
Investigation of Viral Pathogen Profiles in Some Natural Hosts and Vectors in China
}

\author{
Zhiming Yuan ${ }^{1} \mathbb{C}$
}

Received: 6 February 2018 / Accepted: 9 February 2018/Published online: 8 March 2018

(c) Wuhan Institute of Virology, CAS and Springer Nature Singapore Pte Ltd. 2018

China is a vast territory with a wide range of animals and insects that carry complex pathogenic microorganisms. Over the past few years, a rising trend of emerging and virulent infectious diseases has been observed. The outbreak of SARS in 2003 spread to over 32 regions or countries worldwide, resulting in 8422 people being infected and 919 fatalities. The recent outbreaks and endemic epidemics of hand-foot-and-mouth disease (HFMD), H5N1, H7N9, dengue fever, severe fever with thrombocytopenia syndrome (SFTS), and other infectious diseases not only cause serious harm to human health and social stability, but also pose a serious threat to the ecological balance and species diversity.

Among the emerging viral infections, more than $75 \%$ are natural focal diseases. An ecological balance exists between viruses, animal hosts, and vectors. Therefore, once the balance is breached, it may easily give rise to changes in the system population and disease outbreaks. Natural focal viruses generally recycle in wild animals with relatively large populations as natural hosts, such as bats, rodents, and birds, and are transmitted by vectors such as ticks and mosquitoes that co-exist in the specific natural foci.

It is well known that natural hosts and vectors often carry a variety of viral pathogens (Olival et al. 2017; Shi et al. 2016). For instance, 182 viral species, assigned to ten RNA and five DNA virus families, have been found in 75 genera of bats (Ge et al. 2012; Li et al. 2010; Rodhain 2015). In China, a variety of viruses have been detected or isolated in bats, including Japanese encephalitis virus (JEV), chikungunya virus (CHIKV), Roth River virus, coronaviruses, paramyxoviruses, adenoviruses, stellate virus, small RNA virus, adeno-associated viruses,

\section{Zhiming Yuan}

yzm@wh.iov.cn

1 Key Laboratory of Special Pathogens and Biosafety, Wuhan Institute of Virology, Chinese Academy of Sciences, Wuhan 430071, China circoviruses, reoviruses, and rabies virus (Shi 2013). Rodents carry a large number of diverse viruses that range over more than ten viral families, including Arenaviridae, Bornaviridae, Caliciviridae, Flaviviridae, Peribunyaviridae, Picornaviridae, Poxviridae, Reoviridae, and Togaviridae, and at least 21 of the viruses can be transmitted to humans (Huchon et al. 2002; Meerburg et al. 2009; Phan et al. 2011; Zhang et al. 2010). Birds can also carry and spread avian influenza virus (AIV), West Nile virus (WNV), endogenous retroviruses (ERVs), avihepadnaviruses, herpesviruses, poxviruses, adenoviruses, Newcastle disease virus, rotaviruses and others (OIE 2018a). The most notable is AIV, which has been isolated from 100 species of wild birds around the world (Olsen et al. 2006; OIE 2018b).

In addition to the animal hosts, vectors also are significant factors in the transmission of emerging infectious diseases (Shi et al. 2016). In China, there are 124 documented species of ticks, which spread at least 116 types of arboviruses (Gao et al. 2010). Among them, the CrimeanCongo hemorrhagic fever (CCHF, also known as Xinjiang hemorrhagic fever), which is transmitted by the tick Hyalomma asiaticum asiaticum, has been reported several times in the Xinjiang Province of China (Sun et al. 2009). Severe fever with thrombocytopenia syndrome (SFTS) appeared around 2010 in China's Henan, Hubei, Zhejiang, Jiangsu, and other regions, which has been proved to be caused by a novel tick-borne bunyavirus (Yu et al. 2011). In addition, the tick-borne encephalitis virus, which is transmitted by I. persuleatus and Haemaphysalis japonica, is prevalent in the Heilongjiang, Jilin, and Xinjiang areas of China, as well as others, and leads to many fatalities (Xing et al. 2017).

Mosquitoes carry and transmit more than 300 viruses, of which nearly 100 species are known to cause human and animal diseases (Karabatsos 1985; Ng et al. 2011; Liu et al. 2011). The most significant mosquito-borne viruses are the JEV, dengue virus, WNV, Rift Valley fever virus, and CHIKV, among others. Recently, Zika virus has attracted 
Fig. 1 The main natural hosts and vectors investigated in this nationwide survey program. Researchers in the protective suits before starting the field work are in the center. Figures in the panel are provided by the program.

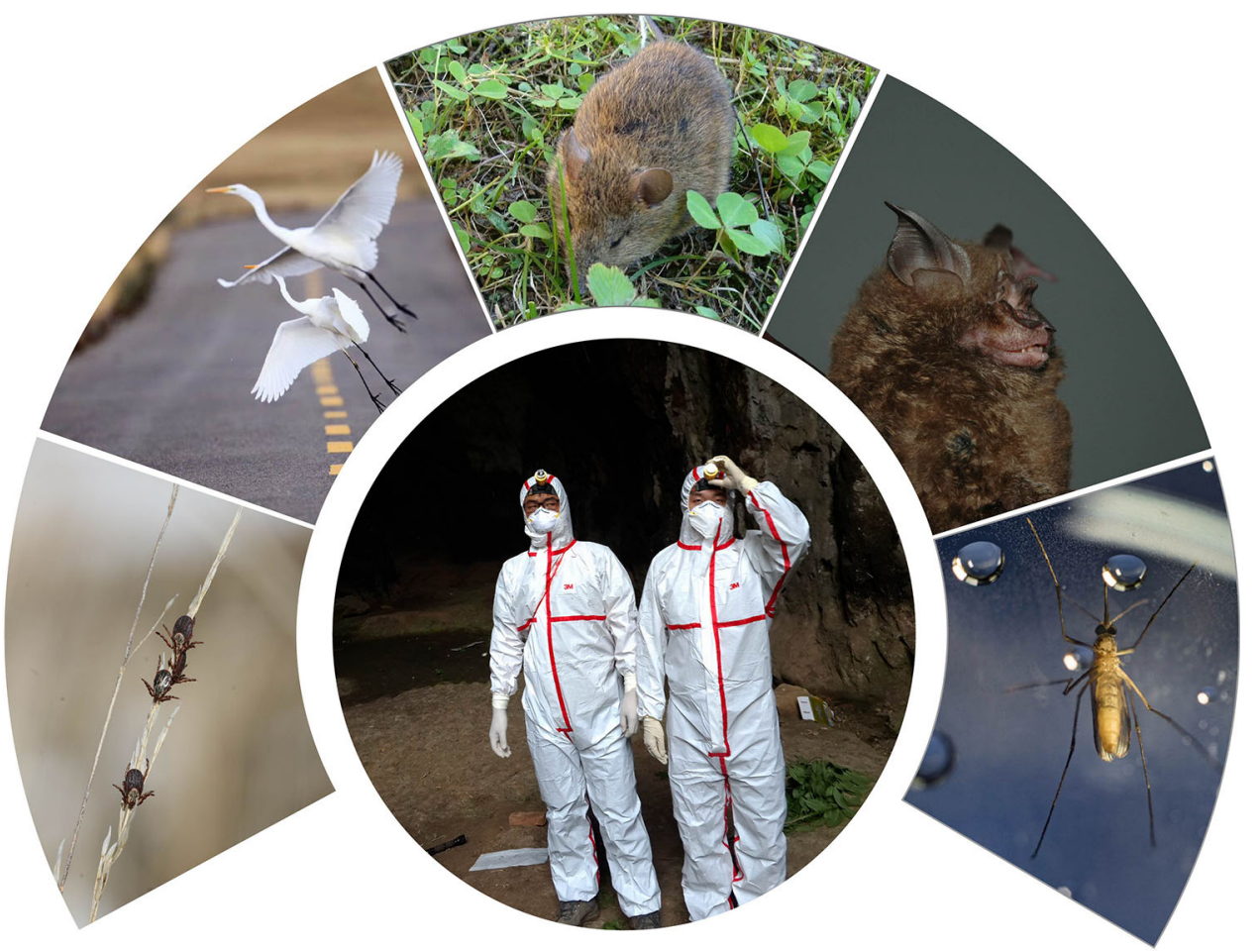

worldwide attention due to its ability to cause congenital brain abnormalities, including microcephaly, and in some cases to trigger Guillain-Barré syndrome (Wang et al. 2016).

Viruses exist and prevail in different natural locations and establish geographic foci of infection based on the distribution of their natural hosts and vectors. Some regions in China have become the epicenters of some important viral diseases because of the particular species and ecology associated with them. For example, Xinjiang province is the natural geographic focus for epidemic tick-borne CCHF and tick-borne encephalitis (Sun et al. 2009). Qinghai province, attributing to the abundant diversity of bird species, provides important breeding and reorganization sites for AIVs (Liu et al. 2005). Hubei province, located in the Central Plains, is a high-frequency area for the rat-transmissible disease hemorrhagic fever with renal syndrome (HFRS) and Japanese encephalitis (Ge et al. 2016; Zheng et al. 2012). Yunnan province is a natural geographic focus of epidemic viral diseases such as rabies (bat-borne), Japanese encephalitis (bat-borne, mosquitoborne), dengue fever (mosquito-borne), tick-borne encephalitis, and others, due to its species richness (Ge et al. 2012; Wang et al. 2011).

While much is known, there remains a lack of systematic studies on the relationship between the spectrum of viruses found and the different species associated with natural epidemic foci of infectious diseases. A program for investigating the main natural hosts and vectors in China has been implemented from 2013 to 2017, which involves a team of researchers across twelve institutions in Xinjiang, Qinghai, Hubei, and Yunnan regions. Over the past few years during the implementation of the program, we have collected more than 100,000 samples originating from bats, birds, rodents, ticks, and mosquitoes. We have successfully isolated 181 novel virus strains, and obtained information regarding the spectrum of viral pathogens and the distribution of their vectors within the survey areas. We have also preliminarily established shareable information databases of these viruses, the metagenomic sequencing reads and contigs database, and shareable virus resources pertaining to bats, mosquitoes, and ticks (http://www.viruses. nsdc.cn/chinavpi/) (Fig. 1).

A portion of the results generated from this program is presented in this special issue. In this issue, Shen and colleagues provide a comprehensive review regarding the current knowledge of worldwide tick-borne viruses (Shi et al. 2018); while a review by Xia et al. systematically summarizes the research progress of mosquito-associated viruses in China (Xia et al. 2018a). Sun and colleagues present their findings on the latest molecular epidemiology of CCHFV in Xinjiang province (Moming et al. 2018), while Deng and colleagues report the isolation and analysis of two novel CCHFV viruses from ticks in Xinjiang (Zhang et al. 2018). The Yuan group reports a comparative metagenomic profiling of viromes associated with four common mosquito species in China, providing an updated status of mosquito viromes in China (Xia et al. 2018b). 
Next, four articles describe the latest research and findings on bat-associated viruses. Longitudinal surveillance of betacoronaviruses in fruit bats in Yunnan province has identified a novel bat HKU9 strain (Luo et al. 2018); a novel hepatovirus from great roundleaf bats in China has been found and characterized (Li W et al. 2018); a novel norovirus in bats has been identified and may be considered as a new genogroup (Yang et al. 2018). In addition, Shi et al. present the serological evidence of bat SARS-related coronavirus infection in humans, and for the first time demonstrate the SARSr-CoV has spillover to humans, although it does not cause clinical diseases (Wang $\mathrm{N}$ et al. 2018). A study involving 278 specimens from seven wild small mammal species in Yunnan province reports two putative novel genotypes of orthohepeviruses from wild rodents (Wang B et al. 2018). Regarding the discovery of AIVs, the occurrence of H7N9 virus in a wild land bird in central China has been reported (Yao et al. 2018), and a multi-analyte suspension assay for simultaneous and efficient detection of AIV A subtypes has been developed ( $\mathrm{Li}$ $Y$ et al. 2018).

It is my hope that the publication of these findings will allow the readers to obtain a better understanding of the importance of investigating pathogen profiles, to realize the extent of viral abundance and diversity in some natural hosts and vectors, and to consider the potential risk of unknown pathogens to the public health.

This special issue would acknowledge to the Basic Work Program of the Ministry of Science and Technology of China, which supports our nationwide survey program regarding the viral pathogen profiling of natural hosts and vectors. And I could also like to thank all authors for their excellent contributions to the special issue, and the editorial office of Virologica Sinica for their great support.

Acknowledgements This work is supported by the Ministry of Science and Technology of China (Basic Work Program 2013FY113500).

\section{References}

Gao X, Nasci R, Liang G (2010) The neglected arboviral infections in mainland China. PloS Negl Trop Dis 4:e624

Ge X, Li Y, Yang X, Zhang H, Zhou P, Zhang Y, Shi Z (2012) Metagenomic analysis of viruses from bat fecal samples reveals many novel viruses in insectivorous bats in China. J Virol 86:4620-4630

Ge L, Zhao Y, Zhou K, Mu X, Yu H, Wang Y, Wang N, Fan H, Guo L, Huo X (2016) Spatio-temporal pattern and influencing factors of hemorrhagic fever with renal syndrome (HFRS) in Hubei Province (China) between 2005 and 2014. PLoS One 11:e0167836

Huchon D, Madsen O, Sibbald MJ, Ament K, Stanhope MJ, Catzeflis F, de Jong WW, Douzery EJ (2002) Rodent phylogeny and a timescale for the evolution of Glires: evidence from an extensive taxon sampling using three nuclear genes. Molec Biol Evol 19:1053-1065

Karabatsos N (1985) International catalogue of arthropod-borne viruses, 3rd edn. American Society for Tropical Medicine and Hygiene, San Antonio (TX)

Li L, Victoria JG, Wang C, Jones M, Fellers GM, Kunz TH, Delwart E (2010) Bat guano virome: predominance of dietary viruses from insects and plants plus novel mammalian viruses. J Virol 84:6955-6965

Li W, Wang B, Li B, Zhang W, Zhu Y, Shi ZL, Yang XL (2018) Genomic characterization of a novel hepatovirus from great roundleaf bats in China. Virol Sin. https://doi.org/10.1007/ s12250-018-0013-6

Li Y, Ni L, Chen J, Yang J, Deng F, Wang H (2018) Development of multi-analyte suspension assay for simultaneously efficient detection of avian influenza virus A subtypes. Virol Sin. https://doi.org/10.1007/s12250-018-0018-1

Liu J, Xiao H, Lei F, Zhu Q, Qin K, Zhang XW, Zhang XL, Zhao D, Wang G, Feng Y, Ma J, Liu W, Wang J, Gao GF (2005) Highly pathogenic $\mathrm{H} 5 \mathrm{~N} 1$ influenza virus infection in migratory birds. Science 309:1206

Liu H, Gao X, Liang G (2011) Newly recognized mosquito-associated viruses in mainland China, in the last two decades. Virol J 8:68

Luo Y, Li B, Jiang RD, Hu BJ, Luo DS, Zhu GJ, Hu B, Liu HZ, Zhang YZ, Yang XL, Shi ZL (2018) Longitudinal surveillance of betacoronaviruses in fruit bats in, Yunnan Province, China during 2009-2016. Virol Sin. https://doi.org/10.1007/s12250018-0017-2

Meerburg BG, Singleton GR, Kijlstra A (2009) Rodent-borne diseases and their risks for public health. Crit Rev Microbiol 35:221-270

Moming A, Yue X, Shen S, Chang C, Wang C, Luo T, Zhang Y, Guo R, Hu Z, Deng F, Sun S (2018) Prevalence and Phylogenetic Analysis of Crimean-Congo Hemorrhagic Fever Virus in Ticks from Different Ecosystems in Xinjiang, China. Virol Sin. https:// doi.org/10.1007/s12250-018-0016-3

Ng TF, Willner DL, Lim YW, Schmieder R, Chau B, Nilsson C, Anthony S, Ruan YJ, Rohwer F, Breitbart M (2011) Broad surveys of DNA viral diversity obtained through viral metagenomics of mosquitoes. PLoS One 6:e20579

Olival KJ, Hosseini PR, Zambrana-Torrelio C, Ross N, Bogich TL, Daszak P (2017) Host and viral traits predict zoonotic spillover from mammals. Nature 546:646-650

Olsen B, Munster VJ, Wallensten A, Waldenström J, Osterhaus AD, Fouchier RA (2006) Global patterns of influenza a virus in wild birds. Science 312:384-388

Phan TG, Kapusinszky B, Wang C, Rose R, Lipton H, Delwart E (2011) The fecal viral flora of wild rodents. PLoS Pathog 7:e1002218

Rodhain F (2015) Bats and viruses: complex relationships. Bull Soc Pathol Exot 108:272-289

Shi Z (2013) Emerging infectious diseases associated with bat viruses. Sci China Life Sci 56:678-682

Shi M, Lin XD, Tian JH, Chen LJ, Chen X, Li CX, Qin XC, Li J, Cao JP, Eden JS, Buchmann J, Wang W, Xu J, Holmes EC, Zhang YZ (2016) Redefining the invertebrate RNA virosphere. Nature 540:539-543

Shi J, Hu Z, Deng F, Shen S (2018) Tick-borne Viruses. Virol Sin. https://doi.org/10.1007/s12250-018-0019-0

Sun S, Dai X, Aishan M, Wang X, Meng W, Feng C, Zhang F, Hang C, Hu Z, Zhang Y (2009) Epidemiology and phylogenetic analysis of Crimean-Congo hemorrhagic fever viruses in Xinjiang, China. J Clin Microbiol 47:2536-2543

The World Organisation for Animal Health (OIE) (2018a) OIE-Listed diseases, infections and infestations in force in 2018. http:// 
www.oie.int/en/animal-health-in-the-world/oie-listed-diseases2018. Accessed 6 February 2018

The World Organisation for Animal Health (OIE) (2018b) Avian Influenza Portal. http://www.oie.int/animal-health-in-the-world/ web-portal-on-avian-influenza. Accessed 6 February 2018

Wang J, Zhang H, Sun X, Fu S, Wang H, Feng Y, Wang H, Tang Q, Liang GD (2011) Mosquitoes, mosquito-borne arboviruses and their infections of Yunnan Province, the China/Burma/Laos border. Am J Trop Med Hyg 84:738-746

Wang Z, Wang P, An J (2016) Zika virus and Zika fever. Virol Sin 31:103-109

Wang B, Li W, Zhou JH, Li B, Zhang W, Yang WH, Pan H, Wang LX, Bock CT, Shi ZL, Zhang YZ, Yang XL (2018) Chevrier's field mouse (Apodemus chevrieri) and Père David's vole (Eothenomys melanogaster) in China carry orthohepeviruses that form two putative novel genotypes within the species. Virol Sin. https://doi.org/10.1007/s12250-018-0011-8

Wang N, Li SY, Yang XL, Huang HM, Zhang YJ, Guo H, Luo CM, Miller M, Zhu G, Chmura AA, Hagan E, Zhou JH, Zhang YZ, Wang LF, Daszak P, Shi ZL (2018) Serological evidence of bat SARS-related coronavirus infection in humans, China. Virol Sin. https://doi.org/10.1007/s12250-018-0012-7

Xia H, Wang Y, Atoni E, Zhang B, Yuan Z (2018a) Mosquitoassociated viruses in China. Virol Sin. https://doi.org/10.1007/ s12250-018-0002-9

Xia H, Wang Y, Shi C, Atoni E, Zhao L, Yuan Z (2018b) Comparative metagenomic profiling of viromes associated with four common mosquito species in China. Virol Sin. https://doi. org/10.1007/s12250-018-0015-4

Xing Y, Schmitt HJ, Arguedas A, Yang J (2017) Tick-borne encephalitis in China: a review of epidemiology and vaccines. Vaccine 35:1227-1237

Yang L, Wang Q, Xu L, Tu C, Huang X, He B (2018) Detection and characterization of a novel norovirus in bats, China. Virol Sin. https://doi.org/10.1007/s12250-018-0010-9

Yao Y, Zhang T, Yang W, Shao Z, He B, Chen X, Wu L, Jin E, Liu $\mathrm{H}$, Chen J, Chen J (2018) Avian influenza A (H7N9) virus in a wild land bird in central China, late 2015. Virol Sin. https://doi. org/10.1007/s12250-018-0001-x

Yu XJ, Liang MF, Zhang SY, Liu Y, Li JD, Sun YL, Zhang L, Zhang QF, Popov VL, Li C et al (2011) Fever with thrombocytopenia associated with a novel bunyavirus in China. $\mathrm{N}$ Engl $\mathrm{J}$ Med 364:1523-1532

Zhang YZ, Zou Y, Fu ZF, Plyusnin A (2010) Hantavirus infections in humans and animals, China. Emerg Infect Dis 16:1195-1203

Zhang Y, Shen S, Fang Y, Liu J, Su Z, Liang J, Zhang Z, Wu Q, Wang C, Abudurexiti A, Hu Z, Zhang Y, Deng F (2018) Isolation, characterization, and phylogenetic analysis of two new Crimean-Congo hemorrhagic fever virus strains from the Northern region of Xinjiang Province, China. Virol Sin. https://doi.org/10.1007/s12250-018-0020-7

Zheng Y, Li M, Wang H, Liang G (2012) Japanese encephalitis and Japanese encephalitis virus in mainland China. Rev Med Virol 22:301-322 